\title{
Effect of Successive Impact Loads From a Drop Weight on a Reinforced Concrete Flat Slab
}

\author{
Ali Jahami $^{1 *}$, Yehya Temsah $^{1}$, Ossama Baalbaki $^{1}$, Mohamad Darwiche ${ }^{1}$, Youmn Al-Rawi ${ }^{1}$, Mohamad Al-Ilani ${ }^{1}$, and Sandy \\ Chaaban $^{1}$ \\ ${ }^{1}$ Beirut Arab University, Civil Engineering Department, Beirut, Lebanon \\ * Corresponding author: a.jahmi@bau.edu.lb
}

\begin{abstract}
Lebanon is one of the countries which are at high risk of experiencing rock falls. In order to ensure public safety, engineers must take into consideration this risk. In the past years, numerous researches were conducted on the behavior of horizontal structural elements, slabs, of different types under dynamic impact load. Reinforced concrete flat slabs are commonly used slabs in residential buildings. To build a profound understanding of the structural behavior of the slabs under such loadings, it is important to investigate the effect of energy dissipation on the equivalent impact force, mid-span deflection and damage pattern. In this study a sample reinforced concrete slab of $500 \times 1000 \times 100 \mathrm{~mm}$ dimensions is considered. The aim of this paper is to find how these factors vary with the increase in energy as the drop load resembling the real rock fall is left to drop freely from different heights $0.6 \mathrm{~m}$ and $1 \mathrm{~m}$.
\end{abstract}

\section{INTRODUCTION}

Rock falls result from the movement of ground. The geological history of Lebanon makes it highly subjected to such hazards. The mode of failure of rock falls differ from rockslides. The former refers to quantities of rocks falling freely while the latter is due to landslides caused by rock failure where part of the ground bed plane of failure passes through compacted rocks and collapses in mass not as individual blocks.

In the previous years, excessive researches have been conducted to study the impact load due to both falling objects and blasts and its effect on slabs and beams [1-7]. The evolution of population and the increase in mobility requirements into and through alpine regions where rock fall hazards are most likely to occur, raises the concern to improve the protection against such inevitable hazards [8]. Therefore, recently, the studies of impact load due to rock fall on slabs are gaining high interest of researchers.

Berthet-Rambaud et al [9] studied experimentally and numerically the effect of impact load on reinforced concrete road sheds in mountain zones. The reinforced concrete sample considered was $12 \mathrm{mx} 4.4 \mathrm{mx} 0.28 \mathrm{~m}$ simply supported over two lines of 11 steel cylinders. The compressive strength was $32.5 \mathrm{MPa}$ and the reinforcement yield strength was $500 \mathrm{MPa}$. Three impacts were carried, two at $15 \mathrm{~m}$ height and one on $30 \mathrm{~m}$. The impact load was a reinforced cube of about $450 \mathrm{~kg}$. The numerical modelling results proved to be in agreement with the experimental measurements where the deflection values measured in the three impacts were approximately equal to the calculated ones.

Tahmasebinia et al [10] examined the same impact effect on reinforced concrete slabs but from the aspect of reinforcement type. Five different samples having $1.355 \mathrm{mx} 1.090 \mathrm{mx} 0.09 \mathrm{~m}$ dimensions were prepared with different shear reinforcements. Two samples were designed without shear reinforcement, two others were designed with vertical shear reinforcement, and the last one with lacing shear reinforcement. The impact load was about $635 \mathrm{~kg}$ from a height of $5.5 \mathrm{~m}$. The results showed that the slabs with shear reinforcement exhibited better structural behaviour against impact loading than the slabs with flexural reinforcement only. In addition, the effect of vertical shear reinforcement was greater than lacing shear reinforcement. This confirms that when designing a reinforced concrete slab against impact, shear reinforcement should be added.

The real behavior and response of slabs to impact loadings require accurate computations of the equivalent impact force, mid-span deflection, and damage pattern. The aim of this study is to investigate the effect of successive impact loads from a drop weight on a scaled reinforced concrete slab focusing on the parameters mentioned previously. The study will help build a profound understanding of the phenomena and the different factors contributing to the structural behavior of Reinforced Concrete (RC) slabs subjected to impact loading. 


\section{EXPERIMENTAL SAMPLE}

\subsection{Size and Geometry}

A $500 \mathrm{~mm} \times 1000 \mathrm{~mm}(l \times w)$ RC slab is casted having a thickness of $100 \mathrm{~mm}$. The slab was reinforced with $5 \mathrm{~T} 10$ steel rebars in the short direction and 4T10 in the long direction. At its boundaries in the short direction the slab is simply supported and shall be restricted from displacement in all directions when applying the different loads, so the boundary conditions shall be prudently set. This is attained by anchoring it to steel beams at the edges as shown in Figure 1. A steel frame is fixed to the ground above the slab to connect the different loads at varying heights before allowing them to fall freely and hit the slab's mid-span; simulating by this the natural rock fall hazards. The drop weight consisted of three different weights $5 \mathrm{~kg}, 10 \mathrm{~kg}$ and $18 \mathrm{~kg}$. Each of them was dropped from two different heights $(0.6 \mathrm{~m}$ and $1 \mathrm{~m})$. The sequence of applied drops is shown in Table 1. Two accelerometers were attached to the bottom face of the slab to measure the acceleration due to impact and the corresponding deflection.

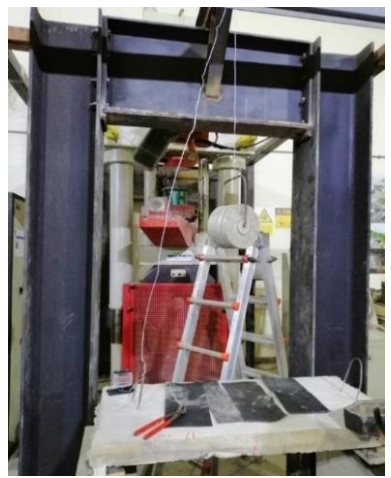

(a)

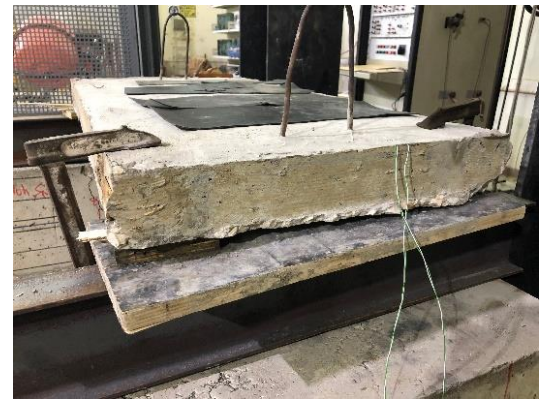

(b)

Figure 1. (a) Experimental Setup (b) Slab Boundary Restraint

\subsection{Material Properties}

The concrete mixture is prepared to have a $25 \mathrm{MPa}$ compressive strength at 28 days. The compressive strength test is performed on four different cylindrical samples of standard dimensions preceding experimental testing to ensure that the concrete reached its desirable strength at 28 days. Figure 2 shows the tested cylinders two days before the first impact was implemented. The steel used in the slab has a yield strength of $420 \mathrm{MPa}$ as provided by the supplier. However, to verify this value the tensile test is performed on the bars and gave $515 \mathrm{MPa}$ yielding strength.
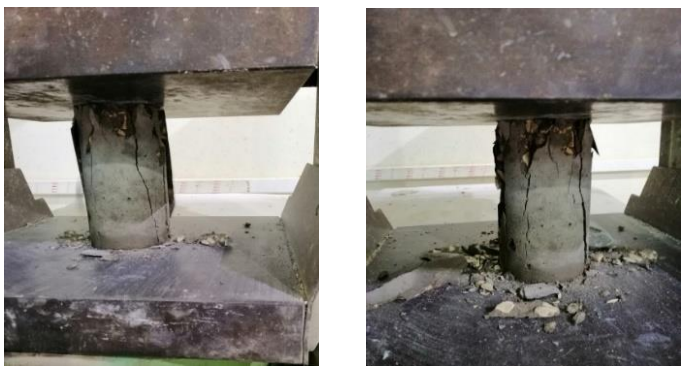

Figure 2. Compressive Strength Test for concrete cylinders

\section{Experimental Results}

Experimental results are summarized in Table 1 below. The applied energy for each drop was calculated based on the gravitational energy equation $\left(E=m^{*} g * h\right)$, where " $E$ " is the gravitational energy, " $m$ " is the drop object mass, " $g$ " is the ground acceleration, and " $\mathrm{h}$ " is the drop height. Another important parameter that was described in Table 1 is the Impact force, which is the multiplication of the drop object mass and the peak acceleration $\left(\mathrm{F}=\mathrm{m}^{*} \mathrm{a}\right)$. Based on the impact force, the Impact factor 
can be determined by dividing the Impact force by the static weight of the drop object. Figure 3 represents the acceleration curve caused by each drop. It can be clearly seen that by increasing the height, the peak acceleration due to drop will increase. Which is by other words due to the increasing energy as the plot in Figure 4 shows. The same conclusion applied for the midspan deflection as shown in Figure 5 where the mid-span deflection was plotted due to each drop. In figure 6, the variation in the slab deflection as a function of applied energy is presented. When the applied energy was $50 \mathrm{~J}$, the slab deflection was around $1 \mathrm{~mm}$. The deflection value continued to increase with the increase in the energy to $6 \mathrm{~mm}$ at $175 \mathrm{~J}$. As the energy increases due to the increase in the mass and gradual increase in the height, the acceleration increases. When the slab is hit, cracks begin formulating at the middle bottom face as shown in figures 7,8 and 9. These cracks are initially observed at the mid-span. As the impact force increases due to the increase in the energy, the crack width increases at the middle of the span and cracks begin to propagate towards the slab edges which is similar to the structural behavior observed in slabs subjected to punching shear. The growth in energy dissipation enlarges the slab deflection. The impact factor that is the behavior magnification of the static load is computed by dividing the impact force by the static force. The experimental work showed the crack patterns due to the different impact loads, where the numerical value at failure is not predictable not even through numerical models since the slab is not subjected to one impact load but to successive impacts. The results obtained through the experiment revealed that to improve the slab response against successive impact loading changing it from one way to two way slab may be a promising solution

Table 1. Results of the Impacts performed on the Slabs

\begin{tabular}{|c|c|c|c|c|c|c|c|}
\hline Drop & $\begin{array}{c}\text { Mass } \\
(\mathbf{k g})\end{array}$ & $\begin{array}{c}\text { Height } \\
(\mathbf{m})\end{array}$ & $\begin{array}{c}\text { Energy } \\
(\mathbf{J})\end{array}$ & $\begin{array}{c}\text { Deflection } \\
(\mathbf{m m})\end{array}$ & $\begin{array}{c}\text { Acceleration } \\
\left(\mathbf{m} / \mathbf{s}^{\mathbf{2}}\right)\end{array}$ & $\begin{array}{c}\text { Impact force } \\
\mathbf{( N )}\end{array}$ & $\begin{array}{c}\text { Impact } \\
\text { factor }\end{array}$ \\
\hline 1 & 5 & 0.6 & 29.4 & 0.61 & 30.00 & 150 & 3.06 \\
\hline 2 & 5 & 1 & 49.1 & 0.80 & 59.30 & 296.5 & 6.04 \\
\hline 3 & 10 & 0.6 & 58.9 & 1.17 & 78.90 & 789 & 8.04 \\
\hline 4 & 10 & 1 & 117.7 & 2.65 & 94.30 & 943 & 9.61 \\
\hline 5 & 18 & 0.6 & 110.7 & 3.43 & 129.20 & 2325.6 & 13.17 \\
\hline 6 & 18 & 1 & 221.3 & 6.04 & 138.00 & 2484 & 14.07 \\
\hline
\end{tabular}

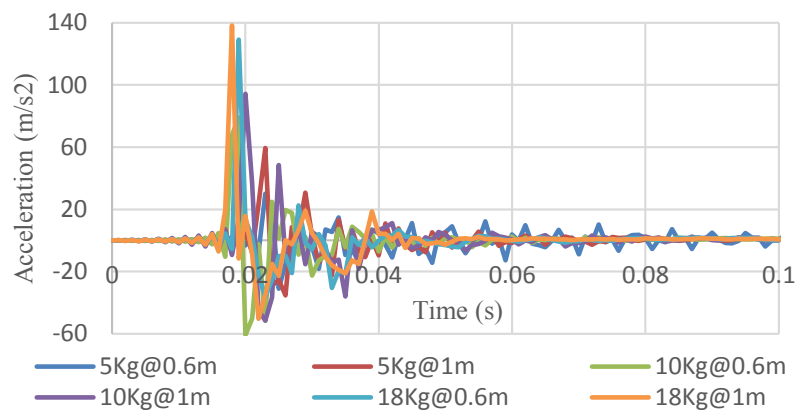

Figure 3. Accelerations from different drops

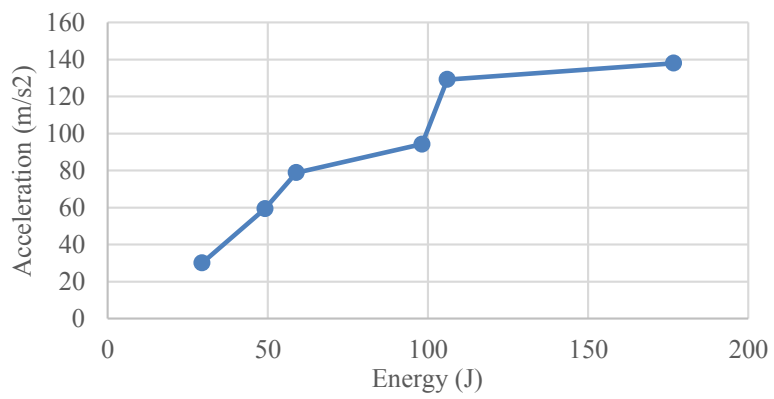

Figure 4. Impact Acceleration as Energy Dissipation Increases 


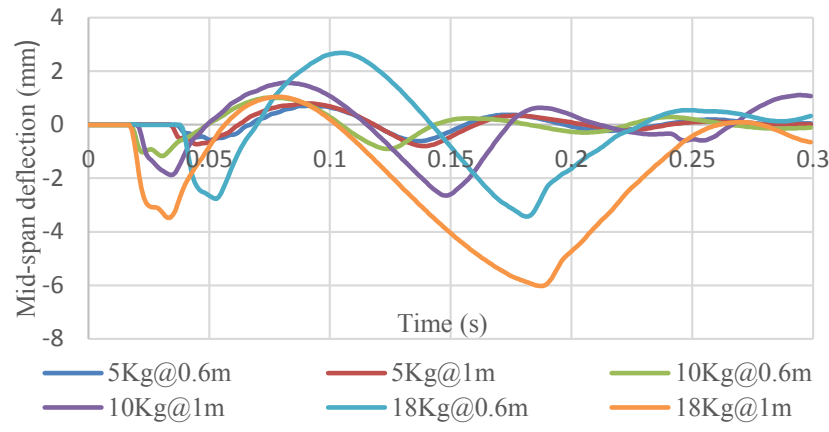

Figure 5. Slab deflections from all drops

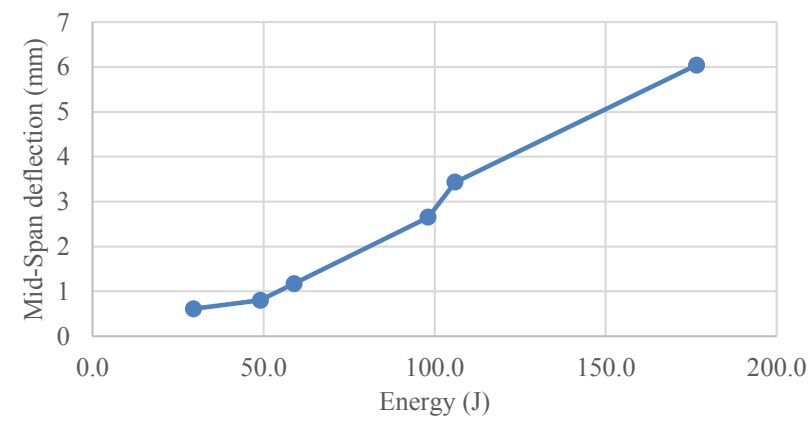

Figure 6. Deflection as Energy Dissipation Increases

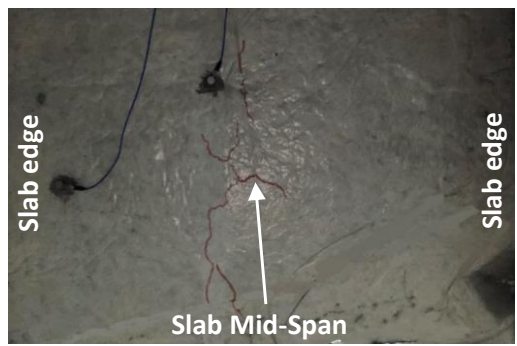

Figure 7. Tensile damage for $10 \mathrm{~kg}$ from 0.6 meters drop height

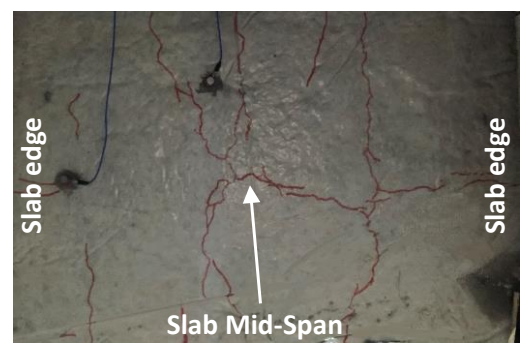

Figure 8. Tensile damage for $10 \mathrm{~kg}$ from 1 meter drop height

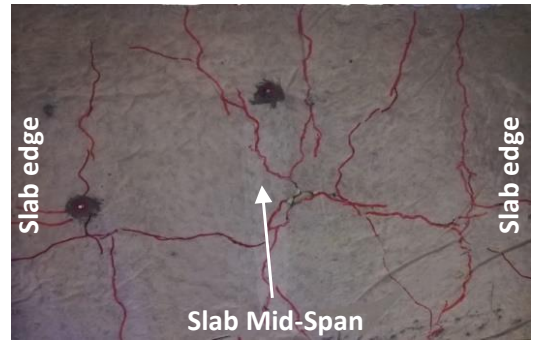

Figure 9. Tensile damage for $18 \mathrm{~kg}$ from 1 meter drop height 


\section{Conclusions}

This paper investigates the behavior of a simply supported slab under drop loads of different weights. The mid-span deflection, impact load factor and damage pattern as the energy increases with the increase in the height were investigated. As the energy increases, the following conclusions can be drawn:

1) The deflection increases due to the flexural behavior of the reinforcement; since the strain-dissipated energy will be greater due to a higher energy drops. In addition, the peak acceleration increases with the increase of the applied energy that is related to both the drop object mass and its height.

2) The impact force amplifies resulting in number of cracks formulation at the tensile zone in the slab giving a behavior similar to slabs subjected to punching shear force.

This can help engineers to develop a profound slab construction to ensure an adequate response to tolerate the impact loadings and decrease risk probabilities.

\section{REFERENCES}

1. Y. Temsah, A. Jahami, J. Khatib, M. Sonebi, Numerical Analysis of a Reinforced Concrete Beam under Blast Loading, MATEC Web of Conferences 149(3):02063, January 2018.DOI: https://doi.org/10.1051/matecconf/201814902063.

2. Y. Temsah, A. Jahami, J. Khatib, M. Sonebi, Numerical Derivation of Iso-Damaged Curve for a Reinforced Concrete Beam Subjected to Blast Loading, MATEC Web of Conferences 149(3):02016, January 2018.DOI: https://doi.org/10.1051/matecconf/201814902016.

3. Y. Temsah, A. Jahami, J. Khatib, S. Firat, (2017). Numerical study for RC beams subjected to blast waves. In: 1st International Turkish World Engineering and Science Congress in Antalya. Antalya, Turkey.

4. Y. Temsah, A. Jahami, J. Khatib, S. Firat, (2017). Single Degree of Freedom Approach of a Reinforced Concrete Beam Subjected to Blast Loading. In: 1st International Turkish World Engineering and Science Congress in Antalya. Antalya, Turkey.

5. Y. Al Rawi, Y. Temsah, H. Ghanem, A. Jahami, and M. Elani. (2018). THEEFFECT OF IMPACT LOADS ON PRESTRESSED CONCRETE SLABS. In: The Second European and Mediterranean Structural Engineering and Construction Conference. [online] ISEC. Available at: https://www.isecsociety.org/ISEC_PRESS/EURO_MED_SEC_02/html/STR-28.xml [Accessed 6 Aug. 2018].

6. M. Elani, Y. Temsah, H. Ghanem, A. Jahami, and Y. Al Rawi. (2018). THE EFFECT OF SHEAR REINFORCEMENT RATIO ON PRESTRESSED CONCRETE BEAMS SUBJECTED TO IMPACT LOAD. In: The Second European and Mediterranean Structural Engineering and Construction Conference. [online] ISEC. Available at: https://www.isec-society.org/ISEC_PRESS/EURO_MED_SEC_02/html/STR-33.xml [Accessed 6 Aug. 2018].

7. A. Jahami, Y. Temsah, J. Khatib, M. Sonebi, "Numerical Study For The Effect of Carbon Fiber Reinforced Polymers (CFRP) Sheets on Structural Behavior of Posttensioned Slab Subjected to Impact Loading", Proceedings of the Symposium on Concrete Modelling - CONMOD2018, RILEM PRO 127, Edited by Erik Schlangen et al., 2018, pp. 259-267.

8. K. Schellenberg, S. G. Khasraghy, S. G. Vogel, Impact Behavior of Reinforced Concrete Slabs Subjected to Rock Fall Loading, Institute of Structural Engineering, Zurich, Switzerland, and June, 2016.

9. Ph. Berthet-Rambaud, J. Mazars, L. Daudeville, Numerical Modeling of Rock fall Impacts on Reinforced Concrete Slabs for the Design of New Rock Sheds, Laboratoire Sols Solides Structures, Grenoble, France, August,2002

10. T. Hrynyk, F. Vecchio, Behavior of Steel Fiber-Reinforced Concrete Slabs under Impact Load, ACI Structural Journal, October, 2014. 